\title{
Aortic annuloplasty: Subcommissural, intra-annular suture techniques, external and internal rings
}

\author{
Jan M. Federspiel, MD, Tristan Ehrlich, MD, Karen Abeln, MD, and Hans-Joachim Schäfers, MD
}

\begin{abstract}
Aortic valve repair and valve-preserving root replacement have evolved into increasingly practiced procedures. With increasing experience, the need for an annuloplasty has become more evident, at least for pathologies that involve annular dilatation. To understand the effect of an aortic annuloplasty, it is necessary to know the details of aortic valve and root anatomy. Geometrically, the functional annulus is best defined as the virtual basal ring, ie, plane of the cusp nadirs. The sinotubular diameter also influences the aortic valve form, at least in tricuspid valves. Different annuloplasty concepts have been developed for isolated valve repair or in combination with root remodeling, such as subcommissural sutures, suture annuloplasty, external, and internal rings. Subcommissural sutures do not consistently provide durable annular stabilization. More positive results have been published for circular approaches, ie, suture annuloplasty, external, or internal rings. The results of different techniques are difficult to judge because most outcome data have not been analyzed with control of confounding predictors of repair failure. The evidence that annuloplasty improves aortic valve function and repair durability is best documented for isolated bicuspid aortic valve repair. In summary, the addition of annuloplasty to aortic valve reconstruction is probably a useful tool to improve valve competence and stabilize the repair. This is best documented for isolated bicuspid valve repair and circular approaches. The relative benefit of individual concepts is difficult to judge because of lack of both control groups and control of confounding factors. (JTCVS Techniques 2021;7:98-102)
\end{abstract}

Repair of the regurgitant aortic valve has increasingly evolved into a reproducible alternative to aortic valve replacement, especially in young individuals. The goal of these procedures is the restoration of normal cusp and root geometry. Of the different techniques, valve reimplantation is designed to correct and stabilize all root dimensions. Root remodeling is thought to provide inadequate annular stabilization, ${ }^{1}$ even though recent data suggest similar annular stabilization using this technique with and without annuloplasty. ${ }^{2}$ The probably greatest need for an

From the Department of Thoracic and Cardiovascular Surgery, Saarland University Medical Center, Homburg/Saar, Germany.

Supported by departmental funding.

Received for publication Dec 9, 2020; accepted for publication Dec 14, 2020; available ahead of print Jan 28, 2021.

Address for reprints: Hans-Joachim Schäfers, MD, Department of Thoracic and Cardiovascular Surgery, Saarland University Medical Center, Homburg/Saar, Germany (E-mail: h-j.schaefers@uks.eu).

JTCVS Techniques 2021;7:98-102

2666-2507

Copyright (c) 2021 The Authors. Published by Elsevier Inc. on behalf of The American Association for Thoracic Surgery. This is an open access article under the CC BY-NC-

ND license (http://creativecommons.org/licenses/by-nc-nd/4.0/).

https://doi.org/10.1016/j.xjtc.2020.12.044

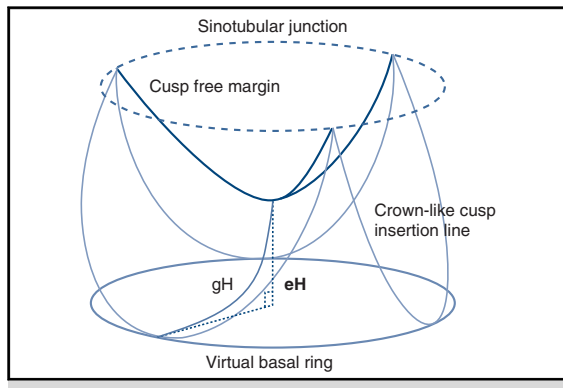

Determinants of aortic valve and root geometry. $\mathrm{gH}$, Geometric height; $\mathrm{eH}$, effective height.

\section{CENTRAL MESSAGE \\ Different annuloplasty concepts}

have been proposed as adjunct

to aortic valve repair when

annular dilatation is present. At

this time, the evidence for their

effectiveness is still soft.

See Commentaries on pages 103,105 , an 107. annuloplasty is in isolated aortic valve repair. For both remodeling and repair, the addition of an annuloplasty to the repair aims at reducing/stabilizing annular dimensions and improving the durability of the repair (at least if annular dilatation is present preoperatively). The primary substrates are regurgitant tricuspid aortic valves (TAVs) and bicuspid aortic valves (BAVs); for the purpose of this review, unicuspid and quadricuspid aortic valves will be spared because they are geometrically different and rare.

\section{ANATOMY OF THE AORTIC VALVE}

To understand the concept of an aortic annuloplasty, it is important to know the anatomic details of aortic valve and root. The aortic valve is a functional unit of cusps suspended within the aortic root. ${ }^{3}$ Geometric alterations of either cusp or root will influence aortic valve form and competence.

The anatomic aortic annulus is best represented by the crown-shaped fibrous structure of the combined cusp insertion lines (Figure 1). ${ }^{4}$ The caudal border of the root, connecting the cusp nadirs in a horizontal plane, has been termed as virtual basal ring. ${ }^{4}$ It is best considered as the true functional annulus because it determines basal valve 


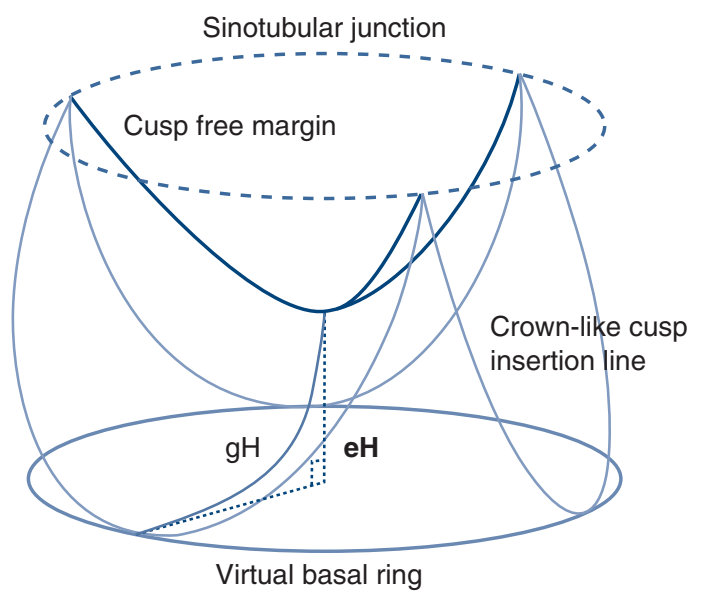

FIGURE 1. Geometric determinants of aortic valve form. Schematic drawing of the geometric determinants of aortic valve form. The anatomic annulus is a crown-shaped structure. The probably more important root dimensions are the virtual basal ring (= functional annulus) and sinotubular junction. $g H$, Geometric height; $e H$, effective height.

geometry. ${ }^{5}$ This functional annulus, termed "annulus" for the purpose of this review, should be the target for all annuloplasty approaches; it also best corresponds to annular size determination by imaging techniques.

The sinotubular junction (STJ; Figure 1) determines the position of the commissures and thus contributes to the anatomy of the aortic valve, at least in TAVs. ${ }^{5}$ Its importance is less clear for bicuspid valves. The contribution of dilatation of the STJ to aortic valve form has long been known. ${ }^{6}$

The ventriculoaortic junction (VAJ) is a different anatomic structure; it is the transition of ventricular myocardium to aortic wall. ${ }^{4}$ The VAJ has been considered as synonymous with the annulus, ${ }^{7}$ but this is potentially misleading. The VAJ can be located at the level of the annulus or more cranially ${ }^{4}$ (Figure 2). In normal TAVs, the difference in location between annulus and VAJ is generally limited. ${ }^{7}$ In BAVs, the distance between the functional annulus and VAJ is usually larger than in TAVs, with up to $15 \mathrm{~mm} .{ }^{8}$ Similar findings may be present in patients with root aneurysms.

The form of the aortic valve depends not only on root dimensions but also on dimensions of the aortic cusps. Geometric height, ${ }^{3}$ ie, the distance from nadir to free margin, and the length of the free margin, ${ }^{3}$ best defines cusp size. A normal aortic valve has a characteristic height difference between the free margins in diastole and the annular plane, termed effective height. ${ }^{3}$ It can be measured intraoperatively and echocardiographically. The length of the free cusp margin is less well characterized. Last but not least, the cusp dimensions differ between tricuspid and bicuspid valves.

\section{ANNULAR DILATATION: CLINICAL AND SIMULATION EVIDENCE}

The size of a normal annulus varies considerably. ${ }^{9}$ Empirically, an annular diameter of more than 25-29 mm has been considered as dilated. ${ }^{1,10}$ Annular dilatation is frequent in aortic regurgitation ${ }^{11}$; it is almost invariably present in regurgitant BAVs. It is also frequent in young patients with tricuspid valves and root aneurysm. ${ }^{12}$ Annular dimension may be underestimated by echocardiography, especially if annular size is determined in diastole, in which the annulus assumes an ellipsoid shape. In children and adolescents, the STJ is generally $20 \%$ smaller than the annulus, ${ }^{13}$ whereas in older individuals, it is larger as the diameter of the normal aorta increases with age.

The clinical effect of annular dilatation on repair durability has been recognized in several studies. ${ }^{10,11}$ Annular dilatation was an independent risk factor for recurrence of

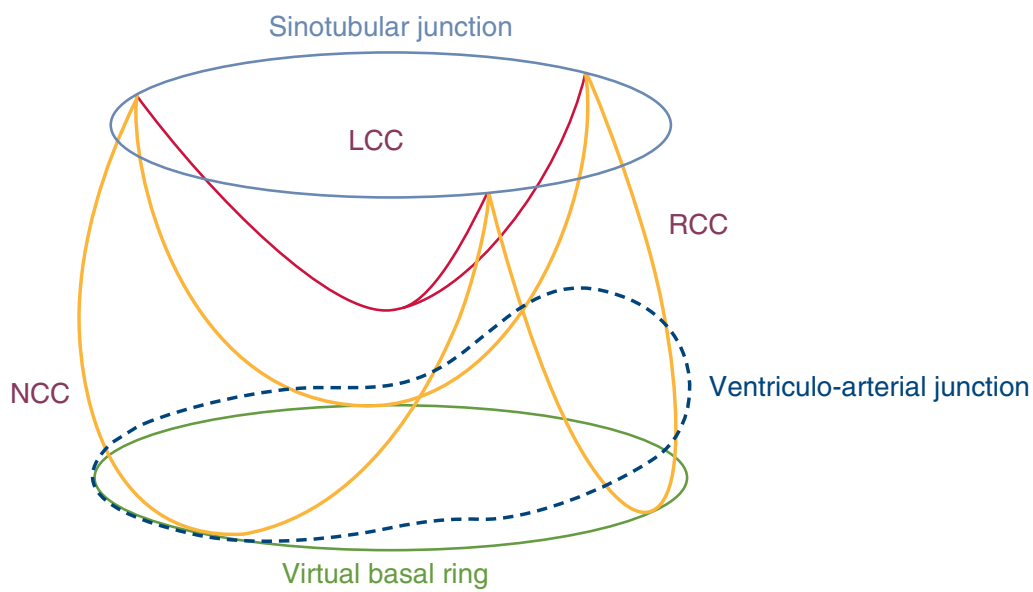

FIGURE 2. Localization of the ventriculoaortic junction. The anatomic ventriculoaortic junction differs from the functional annulus and is best seen by the extent of muscle in the sinus portion of the root. It is not infrequently more than $5 \mathrm{~mm}$ above the level of the annulus, particularly in the right sinus. NCC, Noncoronary cusp; $L C C$, left coronary cusp; $R C C$, right coronary cusp. 
regurgitation in isolated BAV repair. ${ }^{10}$ Stabilizing and/or reducing the aortic annulus at the time of surgery has been shown to significantly improve the durability of BAV repair. ${ }^{11,14}$ Most clinical studies, however, have shown only indirect evidence of the role of annular dilatation. At this time, prospective studies are lacking, and the best evidence for the importance of annular dilatation has been obtained from retrospective studies with BAV repair. ${ }^{10,11}$

The geometric effects of annular dilatation have best been documented for the TAV through computer simulation; this has been shown for annulus and STJ. ${ }^{5}$ With increasing dilatation of the annulus or STJ, coaptation height decreases and finally a central coaptation defect becomes apparent. ${ }^{5}$ These investigations have been performed with a tricuspid valve design; it is unclear to what degree these mechanisms apply to bicuspid valves.

\section{NONANNULAR DETERMINANTS OF AORTIC \\ VALVE REPAIR DURABILITY}

In interpreting the results of studies on aortic valve repair, one has to keep in mind that normal aortic valve form and function depend on the geometry of both valve and root. In clinical studies, a number of confounding factors will influence postrepair function and durability beyond annular dilatation. In addition, the morphology of TAVs and BAVs differs, and it is unclear whether they have comparable repair durability.

In general, an aortic repair depends on the presence of sufficient tissue, ie, geometric height. ${ }^{3,15}$ Lack of tissue will be associated with poor durability. ${ }^{15}$ The reconstructed cusps should have a near-normal form, ie, effective height. ${ }^{3,10}$ Failure to measure effective height has been associated with suboptimal durability. ${ }^{1}$ In bicuspid valves, commissural orientation will also influence repair durability. ${ }^{10,14}$ The use of patch material for cusp repair has been associated with an increased probability of failure. ${ }^{10,14}$ Finally, certain types of repair, such as commissural repairs, also have limited durability.

In effect, an aortic repair procedure can thus be compared with an equation with several variables, in which the annuloplasty is one, while the other variables, ie, predictors of failure, will also influence the result. Keeping this in mind, publications of repair and annuloplasty results must be interpreted cautiously as long as there is no control for the confounding variables.

\section{ANNULOPLASTY CONCEPTS}

Different annuloplasty concepts have been proposed over time by different groups (Table 1). It is currently unclear how frequently the individual approaches are applied in clinical practice. In judging the results reported in the different publications, the details described must carefully considered. Most lack important information, as pointed out in Table 1.

Subcommissural sutures were first proposed by Cabrol and colleagues ${ }^{16}$ and later employed by others, including our group. They are easy to use and commonly placed halfway between annulus and commissures, even though

TABLE 1. Summary of the reviewed series

\begin{tabular}{|c|c|c|c|c|c|c|c|}
\hline Technique & $\mathbf{N}$ [Ref] & $\begin{array}{c}\text { AV } \\
\text { morphology }\end{array}$ & $\begin{array}{c}\text { Valve } \\
\text { assessment }\end{array}$ & $\begin{array}{c}\text { Mean } \\
\text { follow-up, mo }\end{array}$ & $\begin{array}{c}\text { Freedom from } \\
\text { reoperation, } \\
\text { 1-/5-y }(\%)\end{array}$ & Control & Cusp repair \\
\hline \multirow[t]{2}{*}{ Subcommissural suture } & 166 [17] & TAV & $\mathrm{V}$ & NA & NA/NA & + & + \\
\hline & $100[10]$ & BAV & M & 48 & NA/88 & - & + \\
\hline \multirow[t]{2}{*}{ External ring } & $177[1]$ & UAV, BAV & $\mathbf{M}^{*}$ & 41 & $100 / 100$ & - & + \\
\hline & & TAV & & & $97 / 88$ & & \\
\hline \multirow[t]{2}{*}{ Internal ring } & $65[18]$ & TAV & $\mathrm{V}$ & 24 & 95/NA & - & + \\
\hline & 16 [19] & UAV, BAV & M & NA & NA/NA & - & + \\
\hline Internal/external ring & $52[20]$ & TAV & $\mathrm{V}$ & 45 & NA/NA & - & + \\
\hline Double external ring & $37[21]$ & $\begin{array}{l}\text { UAV, } \\
\text { BAV, TAV }\end{array}$ & $\mathbf{M}^{*}$ & 18 & $90 / 75$ & + & + \\
\hline \multirow[t]{2}{*}{ STJ remodeling } & $5[6]$ & TAV & $\mathrm{V}$ & 10 & NA/NA & - & - \\
\hline & $103[12]$ & NA & V & 68 & NA/NA & - & + \\
\hline \multirow{2}{*}{$\begin{array}{l}\text { "Basal" suture } \\
\text { annuloplasty }\end{array}$} & 1024 [14] & BAV & M & 56 & $97 / 94$ & + & + \\
\hline & 164 [23] & BAV & M & 27 & $96 / 93$ & + & + \\
\hline $\begin{array}{l}\text { "Anatomical" suture } \\
\text { annuloplasty }\end{array}$ & $22[25]$ & BAV, TAV & V & NA & NA & - & + \\
\hline
\end{tabular}

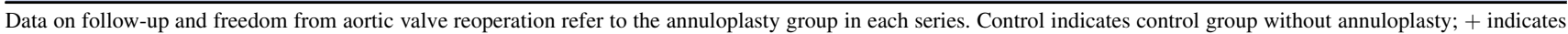
present or was performed; and - indicates not present or was not performed. $N$, Number of individuals with annuloplasty; Ref, reference; $A V$, aortic valve; $T A V$, tricuspid aortic valve; $V$, visual valve assessment; $N A$, not available; $B A V$, bicuspid aortic valve; $M$, objective measurement of valve configuration; $U A V$, unicuspid aortic valve; $S T J$, sinotubular junction. *Not consistent within study. 
this level has never been standardized. Progressive annular dilatation has previously been observed with this technique after BAV and TAV repair, ${ }^{17}$ and they had been associated with repair failure. ${ }^{10,17}$ With the apparent impression that subcommissural sutures do not provide sufficient and stable annular support many surgeons including our group have abandoned this technique.

An external ring was used clinically by Lansac and coworkers, ${ }^{1}$ primarily in conjunction with remodeling. An open ring to be employed for isolated valve repair has been produced by cutting a ring from a Dacron graft; others have used a band primarily designed for mitral repair. The implantation of such an external ring requires dissection similar to that of a reimplantation procedure and may thus be challenging in the presence of discrepancy between VAJ and annulus (Figure 2).

Improved repair stability has been published with the use of such an external ring compared with historical controls in root remodeling ${ }^{1}$ In view of the limited control of confounding factors, it is uncertain to what degree the results are related to the ring alone.

An internal ring was developed based on geometric studies of the aortic root in diastole. ${ }^{18,19}$ The resulting ellipsoid rigid ring (for tricuspid or symmetric bicuspid valves) has rigid extensions toward the commissures. It is to be implanted below the cusp insertion lines and thus seemingly simple to implant using a suture technique similar to implantation of a stented prosthesis.

Good repair results have been published in a several series with limited numbers and follow-up. ${ }^{18,19}$ Some early failures have been related to abrasion of cusp tissue from touching the sutures used for implantation ${ }^{18}$; also, ring dehiscence has been reported. ${ }^{18}$

Fattouch and coworkers ${ }^{20}$ proposed a combination of an internal and external ring. An internal circular Dacron ring is implanted just below the annular plane, and a second, crown-like shaped Dacron ring is sutured externally to the STJ. The 3 vertical extensions of the STJ ring are fixed to the internal one. Little is known on ease of implantation and the use of this approach beyond the initial authors.

More recently, the use of 2 external rings was proposed, ${ }^{21}$ with one ring for the annulus and one for the STJ. The STJ ring appears easy to implant, even though circumferential distortion of commissural position might lead to alteration of valve form. The study found superior results of the double ring compared with the single ring technique regarding need of aortic valve related reintervention. Interestingly, right ventricular ischemia occurred in one instance, possibly related to distortion of the right coronary artery ostium.

The concept of the STJ ring in the double-ring approach is similar to that of tubular aortic replacement for ascending aortic aneurysm and aortic regurgitation, so-called STJ remodeling. ${ }^{6}$ This procedure eliminates STJ dilatation, similar to the external STJ ring. ${ }^{6}$ The procedure is technically easy, although the change of intercommissural distance achieved by the procedure may also distort the valve.

Taylor and colleagues ${ }^{22}$ first designed the concept of a suture annuloplasty placed at basal level. We introduced a modification of the original approach in 2009 into our routine, mainly to accommodate the anatomic variability of VAJ in relation to the annulus and avoid deep myocardial dissection. $^{23}$ A polytetrafluoroethylene suture (Gore-Tex CV-0; W. L. Gore \& Associates, Munich, Germany) is placed to stabilize the annulus at its functional level. ${ }^{23}$ In our experience, we have found that polytetrafluoroethylene as suture material yields the best results. The insertion requires some dissection, but less so than the external ring. Erosion of the membranous septum was observed in very few instances in the early experience and only with braided polyester as suture material, and obstruction of the circumflex occurred in a few instances early on. Positive results were published in 2 series, ${ }^{14,23}$ in which subanalyses allowed for determination of the annuloplasty effect.

Carpentier $^{24}$ proposed a different suture annuloplasty, following the anatomic annulus; others proposed the same technique in a limited series. ${ }^{25}$ This variant is probably easy to perform. Carpentier reported no results. The other series included limited information on results. ${ }^{25}$

\section{CONCLUSIONS}

Aortic valve annuloplasty appears as an important adjunct to aortic valve repair to normalize the functional annulus, ie, basal plane of the aortic root. An annuloplasty will only rarely normalize aortic valve form and function by itself, cusp repair is almost always needed.

For BAV repair, the effect of an annuloplasty has been proven, whereas the evidence is less clear for tricuspid valves. At this time, its benefit in conjunction with root remodeling for BAV is unproven. The evidence in root remodeling for tricuspid valves is soft, even though computer simulation studies indicate that it should improve cusp coaptation and thus valve competence.

In judging the need for an annuloplasty and its clinical benefit, one must consider the limitations in evidence. There is currently no generally accepted definition of annular dilatation requiring correction. Sizing strategies vary, and there is the need to determine and standardize ideal postrepair annular diameter. Finally, very different annuloplasties have been proposed (Table 1). The benefit of subcommissural sutures is questionable, and the results of the other concepts are impossible to compare due to lack of control of confounding predictors of valve durability and inconsistency in published endpoints (Table 1). It is thus impossible to make clear recommendations which technique to choose for which pathology.

Further computer simulation studies and clinical investigations are necessary to better define the risks and benefits 
of the different solutions. Future studies should consistently control for confounding variables and include sufficient follow up, probably at least 5 years.

\section{Conflict of Interest Statement}

Hans-Joachim Schäfers has a consultancy agreement with Cardiac Research and Education, GmbH. All other authors reported no conflicts of interest.

The Journal policy requires editors and reviewers to disclose conflicts of interest and to decline handling or reviewing manuscripts for which they may have a conflict of interest. The editors and reviewers of this article have no conflicts of interest.

We thank Shunsuke Matsushima, MD, for generating the illustrations.

\section{References}

1. Lansac E, Di Centa I, Sleilaty G, Lejeune S, Berrebi A, Zacek P, et al. Remodeling root repair with an external aortic ring annuloplasty. J Thorac Cardiovasc Surg. 2017;153:1033-42.

2. Kunihara T, Arimura S, Sata F, Giebels C, Schneider U, Schäfers HJ. Aortic annulus does not dilate over time after aortic root remodeling with or without annuloplasty. J Thorac Cardiovasc Surg. 2018;155:885-94.e3.

3. Matsushima S, Karliova I, Gauer S, Miyahara S, Schäfers HJ. Geometry of cusp and root determines aortic valve function. Indian J Thorac Cardiovasc Surg. 2020;36(Suppl 1):64-70.

4. Anderson RH. Clinical anatomy of the aortic root. Heart. 2000;84:670-3.

5. Marom G, Haj-Ali R, Rosenfeld M, Schäfers HJ, Raanani E. Aortic root numeric model: annulus diameter prediction of effective height and coaptation in postaortic valve repair. J Thorac Cardiovasc Surg. 2013;145:406-11.e1.

6. Frater RW. Aortic valve insufficiency due to aortic dilatation: correction by sinus rim adjustment. Circulation. 1986;74:I136-42.

7. de Kerchove L, El Khoury G. Anatomy and pathophysiology of the ventriculoaortic junction: implication in aortic valve repair surgery. Ann Cardiothorac Surg. 2013;2:57-64.

8. de Kerchove L, Mastrobuoni S, Froede L, Tamer S, Boodhwani M, van Dyck M, et al. Variability of repairable bicuspid aortic valve phenotypes: towards an anatomical and repair-oriented classification. Eur J Cardiothorac Surg. 2019;56:351-9.

9. Roman MJ, Devereux RB, Kramer-Fox R, O'Loughlin J. Two-dimensional echocardiographic aortic root dimensions in normal children and adults. Am J Cardiol. 1989;64:507-12.

10. Aicher D, Kunihara T, Abou Issa O, Brittner B, Gräber S, Schäfers HJ. Valve configuration determines long-term results after repair of the bicuspid aortic valve. Circulation. 2011;123:178-85.
11. Navarra E, El Khoury G, Glineur D, Boodhwani M, Van Dyck M, Vanoverschelde JL, et al. Effect of annulus dimension and annuloplasty on bicuspid aortic valve repair. Eur J Cardiothorac Surg. 2013;44:316-22.

12. David TE, Feindel CM, Armstrong S, Maganti M. Replacement of the ascending aorta with reduction of the diameter of the sinotubular junction to treat aortic insufficiency in patients with ascending aortic aneurysm. J Thorac Cardiovasc Surg. 2007; 133:414-8.

13. Kunzelman KS, Grande KJ, David TE, Cochran RP, Verrier ED. Aortic root and valve relationships. Impact on surgical repair. J Thorac Cardiovasc Surg. 1994; 107:162-70.

14. Schneider U, Hofmann C, Schöpe J, Niewald AK, Giebels C, Karliova I, et al. Long-term results of differentiated anatomic reconstruction of bicuspid aortic valves. JAMA Cardiol. 2020;16:e203749.

15. le Polain de Waroux JB, Pouleur AC, Robert A, Pasquet A, Gerber BL, Noirhomme $\mathrm{P}$, et al. Mechanisms of recurrent aortic regurgitation after aortic valve repair: predictive value of intraoperative transesophageal echocardiography. JACC Cardiovasc Imaging. 2009;2:931-9.

16. Cabrol C, Cabrol A, Guiraudon G, Bertrand M. Treatment of aortic insufficiency by means of aortic annuloplasty. Arch Mal Coeur Vaiss. 1966;59:1305-12 [in French].

17. de Kerchove L, Mastrobuoni S, Boodhwani M, Astarci P, Rubay J, Poncelet A, et al. The role of annular dimension and annuloplasty in tricuspid aortic valve repair. Eur J Cardiothorac Surg. 2016;49:428-37.

18. Mazzitelli D, Fischlein T, Rankin JS, Choi YH, Stamm C, Pfeiffer S, et al. Geometric ring annuloplasty as an adjunct to aortic valve repair: clinical investigation of the HAART 300 device. Eur J Cardiothorac Surg. 2016;49: 987-93.

19. Mazzitelli D, Pfeiffer S, Rankin JS, Fischlein T, Choi YH, Wahlers T, et al. A regulated trial of bicuspid aortic valve repair supported by geometric ring annuloplasty. Ann Thorac Surg. 2015;99:2010-6.

20. Fattouch K, Castrovinci S, Murana G, Nasso G, Guccione F, Dioguardi P, et al. Functional annulus remodelling using a prosthetic ring in tricuspid aortic valve repair: mid-term results. Interact Cardiovasc Thorac Surg. 2014; 18:49-54.

21. Zakkar M, Bruno VD, Zacek P, Di Centa I, Acar C, Khelil N, et al. Isolated aortic insufficiency valve repair with external ring annuloplasty: a standardized approach. Eur J Cardiothorac Surg. 2020;57:308-16.

22. Taylor WJ, Thrower WB, Black H, Harken DE. The surgical correction of aortic insufficiency by circumclusion. J Thorac Surg. 1958;35:192-205. passim.

23. Schneider U, Hofmann C, Aicher D, Takahashi H, Miura Y, Schäfers HJ. Suture annuloplasty significantly improves the durability of bicuspid aortic valve repair. Ann Thorac Surg. 2017;103:504-10.

24. Carpentier A. Cardiac valve surgery-the "French correction." J Thorac Cardiovasc Surg. 1983;86:323-37.

25. Schöllhorn J, Rylski B, Beyersdorf F. Aortic valve annuloplasty: new single suture technique. Ann Thorac Surg. 2014;97:2211-3.

Key Words: aortic valve, annuloplasty, aortic valve reconstruction 